\title{
An index of financial market stress for the United Kingdom
}

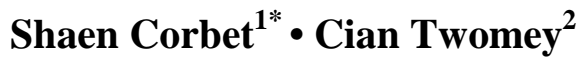 \\ ${ }^{1}$ Dublin City University, Ireland \\ ${ }^{2}$ National University of Ireland, Ireland
}

Received: 2 July 2014

Revised: 25 September 2014

Accepted: 26 September 2014

\begin{abstract}
We construct and develop a new financial market stress index using twenty-three headline UK financial data series. A logistic regression framework provides a parsimonious representation of financial market stress in the UK based on the market dynamics around the time of Bank of England crisis-alleviating economic interventions. Our results present clear evidence that the Bank of England's swift and decisive actions stemmed financial market stress as measured by the stress index.
\end{abstract}

Keywords: financial crises, financial markets, financial stress indicator JEL Classification Codes: G01, G15

\section{Introduction}

The role of crises and stress measurement has become a widely investigated research area in the aftermath of the global financial crisis. However, there is a large gap in the literature on constructing an index of United Kingdom-specific financial market stress, a metric measured in other countries such as the United States and Japan.

The United Kingdom stress index described here builds on the recent US methodology of Carlson, Lewis and Nelson (2012) and the European-specific methodology developed by Corbet (2014). Twenty-three of the most common financial metrics of United Kingdom financial market stress are included in this index, designed specifically to capture stress across market risk, market uncertainty and market liquidity.

Similar to the work of Nelson and Perli (2005), the index is constructed using three subindices: the constituent series levels; the change in volatility; and the co-movement of the selected variables. The levels provide evidence of large movements in the series, monitoring direct market perceptions of market risk. The volatility of the constituents increases based on

\footnotetext{
*Corresponding author. E-mail: shaen.corbet@dcu.ie.

Citation: Corbet, S. and C. Twomey (2014) An index of financial market stress for the United Kingdom, Economics and Business Letters, 3(2), 127-133.
} 
the aggregation of market stresses and the co-movement is found to increase drastically during periods of crisis (Kaminsky and Reinhart, 2001).

The index denotes a period as being 'in crisis' when the Bank of England (BOE) implements an interest rate decrease or undertakes quantitative easing (QE) to ease the effects of any financial stress. A dummy variable is incorporated to capture the two weeks before and two weeks after the relevant BOE decision. We then use a logistic regression model to estimate the coefficients used to create the UK stress index. Through this process, the index can be interpreted as 'identifying the degree to which conditions in the UK financial markets are similar at present to those when BOE policy-makers saw fit to intervene'.

Several pertinent variables are selected based on their contribution to the index within the parameters of market liquidity, risk spreads and investor uncertainty. Each component contributes to the overall index through the addition of information based on changing financial market stress, evaluated on current and historic conditions through the use of a logistic regression framework. This methodology was found to be the most compatible due to its adaptive and self-learning characteristics. Although specifications such as Markovswitching, GARCH, and EGARCH were also analysed, the logistic framework provided the most theoretically and statistically robust results. The other tested methodologies struggled to incorporate periods of non-crisis related illiquidity in the late 1990s and early 2000s and specifically misidentified a number of periods as being in crisis when they were not. The logistic framework identified crisis in this period attributable to the dot-com collapse, but did not identify 'false crises' as obtained in the specifications modelled. This illiquidity may be attributed to the immaturity and underdevelopment of a number of UK financial products and markets.

Recent attempts to focus on financial market stress include Illing and Lui (2003), Grimaldi (2010) and Louzis and Vouldis (2011), with the latter using a multivariate GARCH methodology to incorporate time-varying correlations between markets. Hollo, Kremer and Lo Duca (2012) applied basic portfolio theory to five sub-indices based on European markets. The US Federal Reserve Banks of St. Louis, Kansas and Cleveland remain the pioneers of stress indices. The Cleveland stress index created by Oet et al. (2011) parsimoniously represents the trends and dynamics of numerous United States stress indicating variables. Our index is the first of its kind based on UK financial markets.

\section{Theoretical background}

The UK-specific stress index incorporates components that quantify individual aspects of the financial system, combining them into a single indicator, designed using daily data and reflecting twenty-three components based on credit, equity, foreign exchange and interbank markets (listed in Table 1). The components are categorised based on liquidity, risk spreads and investor uncertainty, which present evidence of financial market stress sourced from reduced trading levels, higher levels of perceived risk and negative investor perceptions, respectively. The corresponding variables selected are the most common financial market representations for each of the differing aspects. Financial stress in any of the investigated areas can freely transfer from one constituent market to the next.

To enable comparability within the series, each individual component is standardised. To reduce noise, the index is smoothed using a five-day moving average. This UK-stress index is designed to offer a point-in-time estimate of financial market stress based on dynamic spreads that react based on investor perceptions of both present and future market conditions. This allows analysts and policy-makers to monitor stressful situations as they are developing, aiding decision-making, monetary policy and macro-prudential regulation. 
Table 1. Individual components of the UK stress index

\begin{tabular}{|c|c|}
\hline Component & Description \\
\hline \multicolumn{2}{|l|}{ Liquidity } \\
\hline 1 & Spread between BOE financing offered rate and the yield on 3-month LIBOR \\
\hline 2 & Spread between official BOE rate and the yield on 1-month LIBOR \\
\hline 3 & Spread between official BOE rate and the yield on 3-month LIBOR \\
\hline 4 & $\begin{array}{l}\text { Trade-weighted ratio of current price relative to previous } 365 \text {-day peak for GBP/USD. GBP/CHF, GBP/JPY and } \\
\text { GBP/EUR }\end{array}$ \\
\hline 5 & Spread between 3-month LIBOR and 3-month Sterling mean interbank lending rates \\
\hline 6 & Spread between 3-month LIBOR and 10-year UK Government bond \\
\hline \multicolumn{2}{|r|}{1} \\
\hline 7 & Spreads between yields of AAA UK corporate bonds and 10-year UK Government bond \\
\hline 8 & Spreads between yields of BBB UK corporate bonds and 10-year UK Government bond \\
\hline 9 & Spread between the yields of high yielding UK corporate bonds and 10 -year UK Government bond \\
\hline 10 & Spread between yields of >10-year (LT) UK corporate bonds and 10-year UK Government bond \\
\hline 11 & Spread between 3-month LIBOR and 3-month US Treasury-bill \\
\hline 12 & Spread between 3-month LIBOR futures and 3-month Sterling mean interbank lending rates \\
\hline 13 & Spread between 10-year UK government bond yield and the 10-year US Government bond yield \\
\hline \multicolumn{2}{|c|}{ Investor uncertainty } \\
\hline 14 & Spread between 3-month LIBOR and 10-year UK government bond yield \\
\hline 15 & Ratio of current FTSE100 price index relative to previous 365-day peak \\
\hline 16 & UK 10-year government bond yield implied volatility \\
\hline 17 & 30-day FTSE100 option implied volatility index \\
\hline 18 & $\begin{array}{l}\text { Ratio of FTSE100 financials index relative to FTSE100 index relative to the ratio of spot values of each, relative to } \\
\text { their previous } 365 \text {-day high value }\end{array}$ \\
\hline 19 & Spread between FTSE100 returns and the 10 -year UK government bond yield \\
\hline 20 & FTSE100 index of EPS as expected and announced \\
\hline 21 & LIBOR futures implied volatility \\
\hline 22 & 1-year forward 1-year swaption implied volatility (GBP vs LIBOR) \\
\hline 23 & 1-year forward 10-year swaption implied volatility (GBP vs LIBOR) \\
\hline
\end{tabular}

Note: The data used to comprise the components of the indicator was taken from Bloomberg and Thompson Reuters Datastream

The index segregates the smoothed series into three sub-indices. The first is based on the levels of the included data, designed using an un-weighted average of the twenty-three individual components which can be viewed in figure 1. The second component of the underlying series is the volatility of the constituent assets which can be viewed in figure 2 . This measure tracks the risk and liquidity spreads during episodes of crises. Kritzman et al. (2010) found that these spreads and the prices of risk assets remain especially sensitive to news as a crisis develops. Volatility is measured using the sum of squared daily changes.

Figure 1. Constituent variable levels

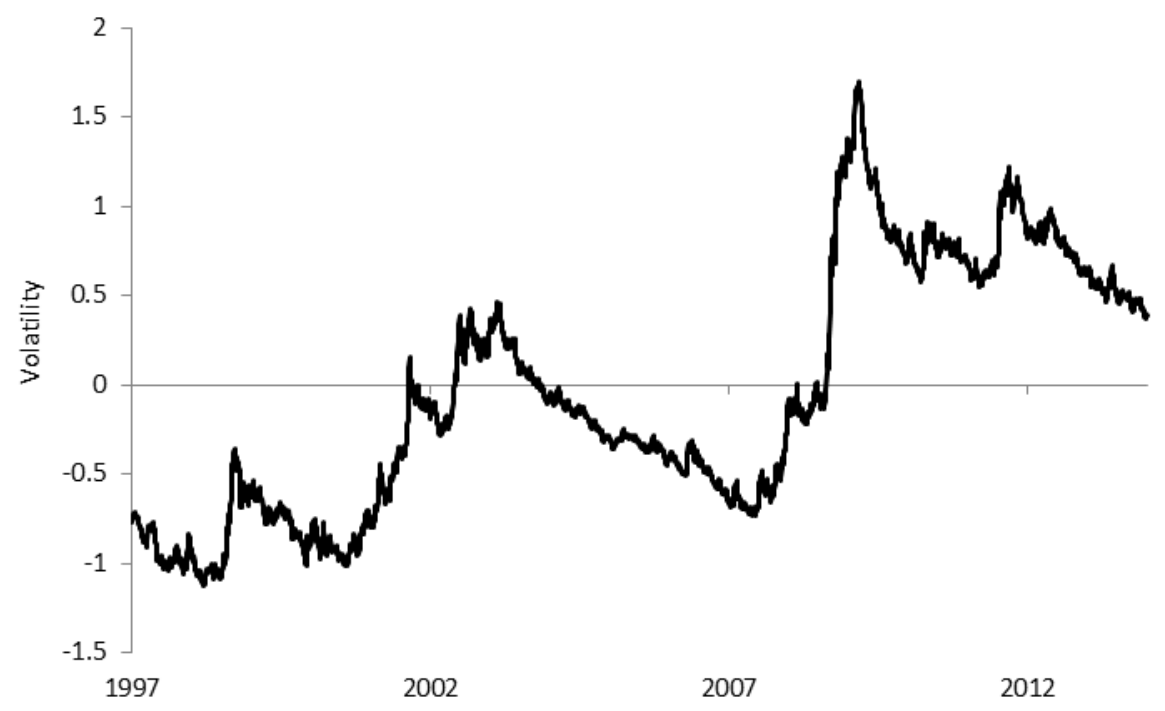

Note: This series is the average of the twenty-three standardised variables, which are each expressed as the number of standard deviations they are from their own long-run mean. 
Figure 2. Constituent variable volatility

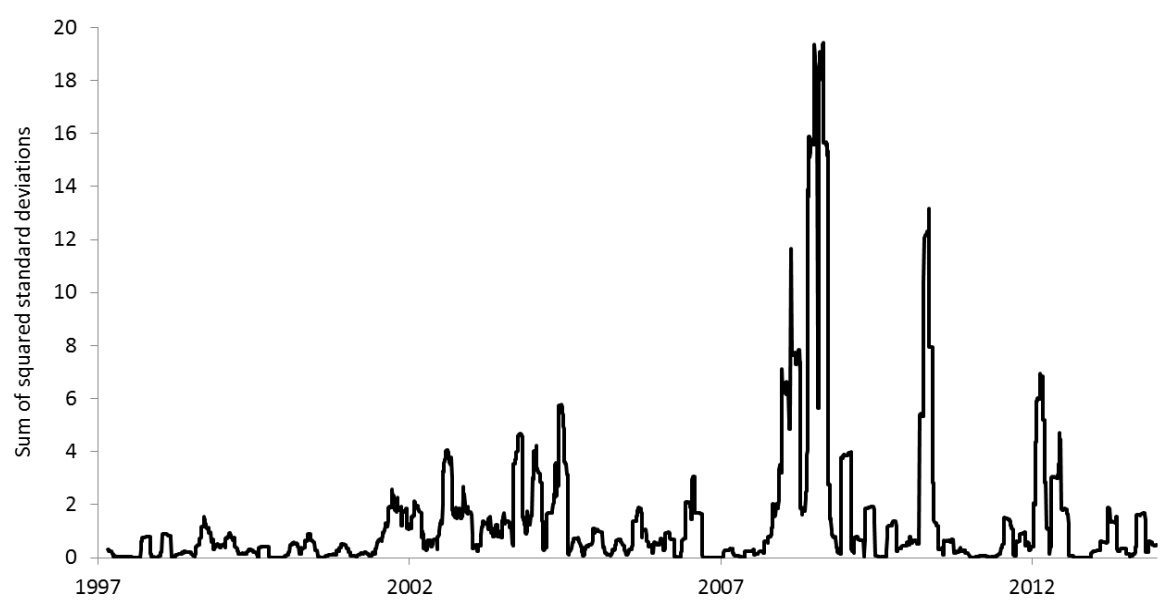

Note: The volatility series is the sum of the squared changes in the data over an eight-week rolling window and is designed to capture changes in the level of volatility in the twenty-three underlying financial market variables.

During financial stress episodes, asset prices tend to move together as market correlations tend to one. To capture this dynamic, the first principal component based on the changes of the twenty-three variables is calculated. The higher the value of this measure, the more of the changes in the underlying index can be explained by a single common factor, indicative of a stressful financial episode.

To combine the three sub-indices, we look at the financial market pressure alleviation tactics used by the BOE. These decisions include a cut in the base interest rate and the implementation of quantitative easing, designed to stem crisis situations and promote economic growth. The four week period around these decisions is designed to capture the dynamics of the economic environment on which to use the logistic regression framework. The logit model used to create the UK stress index is regressed on the three sub-indices denoted as levels (lev), changes in volatility (vol) and constituent co-movements (com). Specifically, the model takes the form:

$$
p_{\log i t}=P\left(\beta_{0}+\beta_{l e v} l e v+\beta_{c o l} c o l+\beta_{c o m} c o m\right)
$$

As we use a logistic regression framework to derive the coefficients of the index, we can also interpret the stress index as a probability of the UK financial markets being in a period of financial stress. This is estimated as:

$$
p_{\text {prob }}=\frac{e^{\left(\beta_{0}+p_{\log i t}\right)}}{1+e^{\left(\beta_{0}+p_{\log i t}\right)}}
$$

The sense in which this stress index is expressing a probability is limited to the context of identifying current market conditions. The base index without the implementation of a fiveday moving average is used to produce a more parsimonious probability measure. The index should be considered a statistical measure of the similarity between current United Kingdom financial conditions and those that have prevailed at a time of crisis, deemed as the time in which the BOE saw fit to intervene in financial markets. 
Figure 3. Constituent variable co-movement

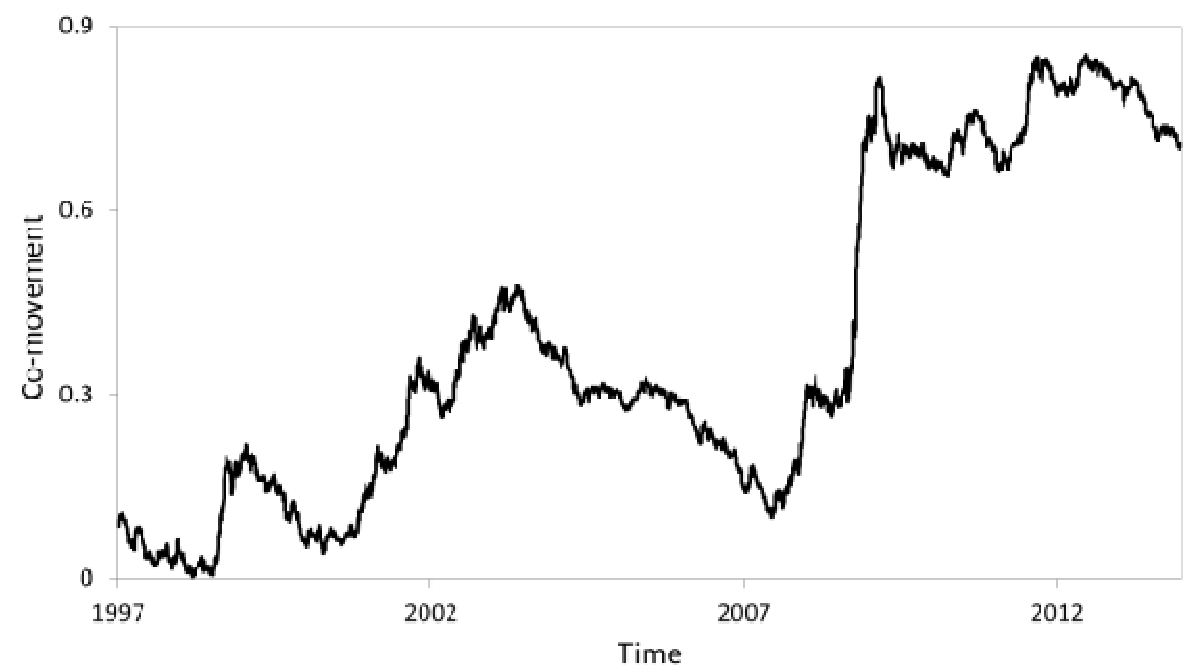

Note: We computed the variable co-movement using the first principal component (PCA) of the constituent variables.

\section{Empirical analysis}

The co-movement of the variables in the UK stress index offers some interesting results. This can be seen in figure 3 where there is an evident sharp increase in 2007 after the beginning of the U.S. subprime crisis. This co-movement has remained elevated since, remaining at 70 per cent through to early 2014.

The logistical regression framework is first used to estimate the coefficients of the weighted-sum and probabilistic models. The results are found in table 2.

Table 2. Logistic regression model estimation results

\begin{tabular}{lcccc}
\hline \hline & Estimate & St. Error & Z value & Prob (>IzI) \\
\hline \hline Intercept & 1.8274 & 0.2291 & 11.20 & 0.000 \\
Lev & 3.7379 & 0.2942 & 14.90 & 0.000 \\
Vol & -0.0354 & 0.0481 & -9.46 & 0.000 \\
Com & -8.8557 & 0.5881 & -4.97 & 0.000 \\
\hline \hline
\end{tabular}

Note: These results are the estimated coefficients of the logistic regression model used to estimate the weighted-sum and probabilistic models.

The logistically calculated UK stress index is denoted in figure 4. We can see the clear elevation in financial market stress in the period around mid-2008. Though the U.S. subprime crisis began in 2007, it appears that UK-specific financial market stress did not peak until nearly one year later. This high-stress episode lasted over one year, whereas there is clear alleviation of pressures from 2009 onwards. This can be interpreted as the result of BOE intervention in the UK banking system and the UK economy directly through the implementation of quantitative easing. 
Figure 4. The UK financial market stress index

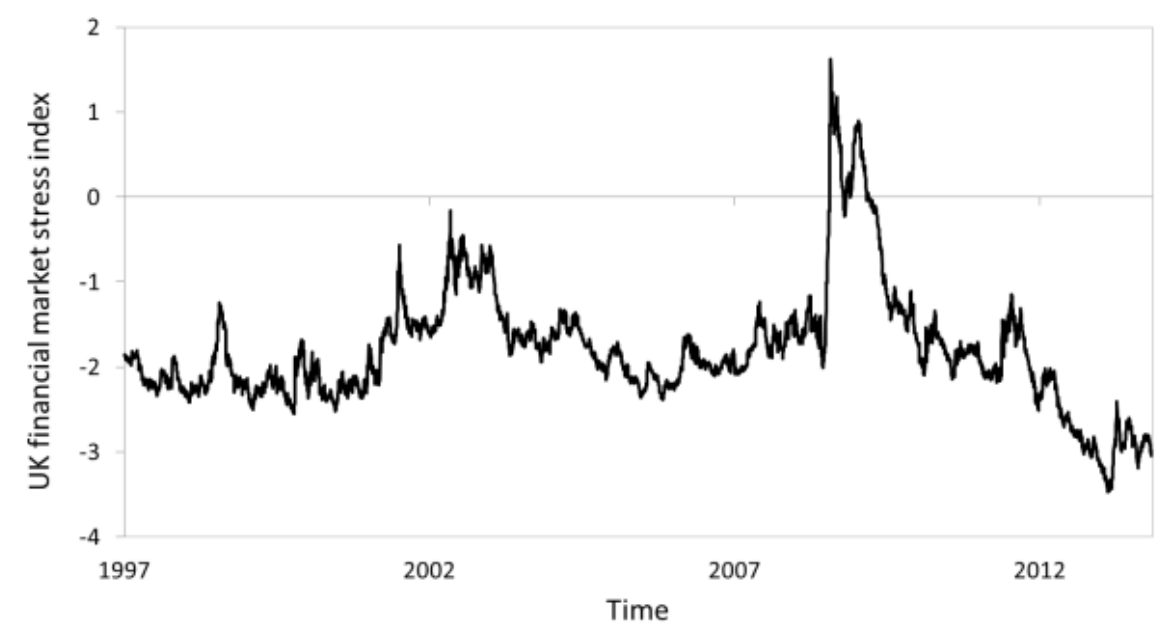

Note: The UK financial market stress index is compiled based on the twenty-three underlying constituent variables.

Figure 5. Stress indicator probability of crisis

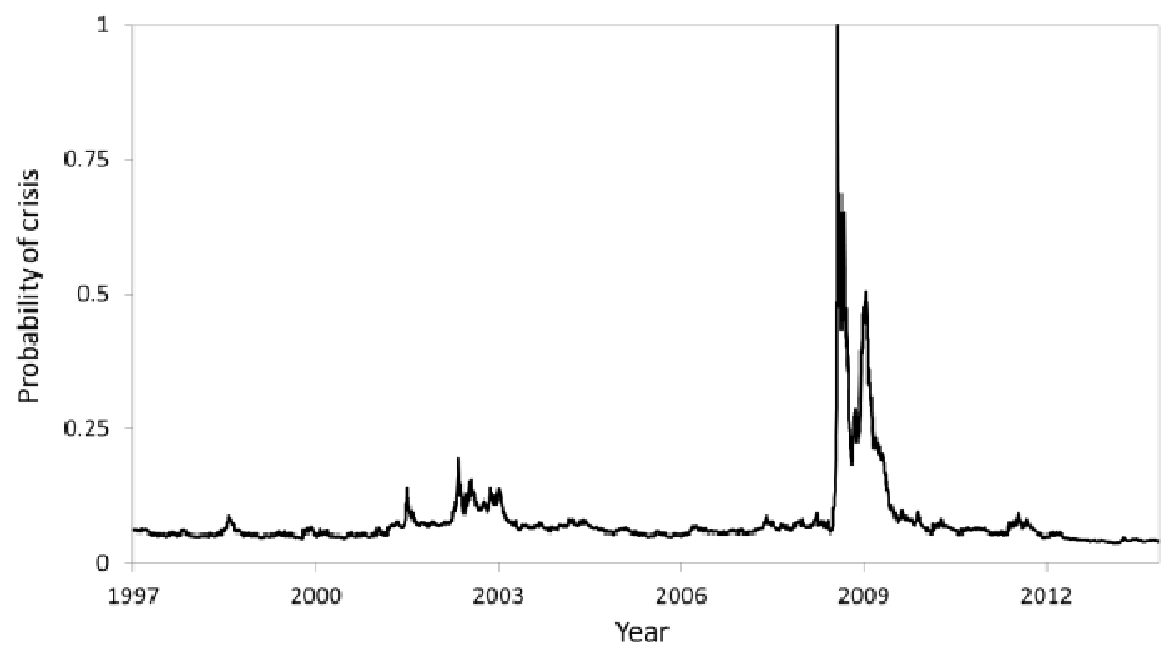

Note: This probability measure is derived from the UK stress index. Non-standardised data is used to generate the probability measure, therefore the use of a five day moving average is negated.

From a probabilistic standpoint, despite some elevated risks of crises between 2001 and 2003, the period between mid-2008 and mid-2009 remains the sole period where the UK economy can be identified as being in evident "crisis" as defined by our UK financial market stress index. As indicated in figure 5, since late-2011 the probability of being in a crisis has decreased substantially to less than 4 per cent after swift and direct action by the BOE.

\section{Concluding remarks}

Our empirical analysis constructs and develops a financial stress index based on United Kingdom financial markets. This is achieved through the incorporation of twenty-three headline UK financial data series. A logistic regression framework provides a parsimonious representation of financial market stress in the UK based on the market dynamics around the time of BOE crisis-alleviating economic interventions. The results present evidence that the 
BOE's swift and decisive actions stemmed financial market stress as measured by the indicator, offering substantial support towards the use of these mechanisms as methods of ameliorating future financial market stress and crises.

\section{References}

Carlson, M., Lewis, K. and Nelson, W. (2014) Using policy intervention to identify financial stress, International Journal of Finance and Economics, 19(1), 59-72.

Corbet, S. (2014) The European financial market stress index, International Journal of Economics and Financial Issues, 4(1), 217-230.

Grimaldi, M. (2010) Detecting and interpreting financial stress in the Euro area, Working Paper Series, 1214, European Central Bank.

Hollo, D., Kremer, M. and Lo Duca, M. (2012) CISS - a composite indicator of systemic stress in the financial system, Working Paper Series, 1426, European Central Bank.

Illing, M. and Liu, Y. (2003) An index of financial stress for Canada, Working Papers, 03-14, Bank of Canada.

Kaminsky, G.L. and Reinhart, C.M. (2002) Financial markets in times of stress, Journal of Development Economics, 69(2), 451-470.

Louzis, D. and Vouldis, A. (2013) A financial systematic stress index for Greece, Working Paper Series, 1563, European Central Bank.

Nelson, W.R. and Perli, R. (2007) Selected indicators of financial stability, Irving Fisher Committee's Bulletin on Central Bank Statistics, 23(2005), 92-105.

Oet, M.V., Eiber, R., Bianco, T., Gramlich, D. and Ong, S. (2011) The financial stress index: identification of systemic risk conditions, Working Paper 11-30, Cleveland Federal Reserve Bank. 